\section{Index of Subject}

advantages 18-20, 28, 76, 119, 157, 204, 206

agglomeration 96, 241

border effect 72, 116

comparative advantage 213

competitiveness 2, 8, 14, 38, 99, 202-205, 212, 217

convergence 190, 236

Dutch disease, DD 2, 53, 55-56, 139, 220, 224, 226, 230-231, 233-234, 236, 239-240, 243, 245-246, 248-249

economic growth $2,19,25-26,29,34,36-37,40$, $42-50,52,55-56,60-61,71,80,82-83,143$, $160,176,183,205,220,224-230,234,237$, 239-249

economic shocks 58, 96-97, 102, 159, 221-223

economies of scale $11-12,21,31-35,61,67-68$, 73,220

exchange rate $16,42-43,53-54,57,66,70$, $75-76,119,142,204,225,233$

export gap 70, 234

export intensity 9, 20, 66, 76, 89, 102, 223

export potential 69-70, 136, 197, 216, 223

exports agglomeration 68

externalities 19, 30-31, 34, 36-37, 68, 70, 73, 75, 103, 229, 242

factor endowment 7, 9-10, 13

fixed costs 20,63

Foreign owned entity, FOE 20, 22-23, 60

Foreign Direct Investment, FDI 2, 7, 11-12, 18-22, 27-28, 30, 42, 45-46, 48-53, 57, 59-60, $72-73,75-76,103,106,119,124,126,136$, $169,188,221-230,237-241,243,247-249$

Free Trade Agreement, FTA 146, 150, 156, 166, 182, 226, 236, 238-239, 248

global technology frontier, GTF 27, 29

gravity model 6-7, 64-65, 72, 75, 116, 118-120, $124,136,139,161,165,221,224,231,239$, 245, 249

heterogeneity $1-2,7,11,15-16,18,20,23,25-27$, $33,38,40,50,67,69,71,104,115-116$, $120,139,147,157,160,182,210,216,221$, 244-245

home market effect, HME 29, 31, 35, 38, 69, 226 indigenous firms 18-19, 229

Industry mix effect 64

inland regions $46,60,75$ innovation $11,18,22,27-28,30,37-38,43,48$, $52,59,73,138,186,188-189,191-193,196$, 202-203, 205-206, 225, 227-229, 235, 237, 239-240, 243, 249

internationalisation 38, 59, 61, 186, 193-196, 198-201, 223, 228, 243

Intra-industry trade, IIT 6-7, 10-12, 15, 19-20, 73, $76,102,104-106,109-110,187$, , 220, 228, $237,242,250-251$

lagging regions 27,45

learning-by-exporting 28-29

localisation 7, 70, 220

love for variety $11-12,104$

location quotient, LQ 67, 88-89, 173, 209-210

Marshallian externalities 31, 254

multi-national enterprise, MNE 18-19, 230

new economic geography, NEG 1-2, 7, 16, 23-25, $30-40,47,56,69,96,220,226-227,235$, 238, 240, 242, 245, 248, 250

Marshallian externalities 31

NNEG 2, 16, 38, 40, 52

openness 2 , 9, 14, 16, 18, 25-27, 29-30, 32-33, $39-40,42-50,52,60,73-74,76,80-83,85$, $102-103,110,125,138-139,150,154-159$, $161,167-170,176-181,183,186,220-221$, 228, 234, 237, 241, 243, 246-247, 251-252

productivity $1,7-8,15,17-18,20,24,27-29,35$, $38-39,43,47-48,51,53-55,59,63,69,136$, 142, 192, 202-205, 223-224, 228, 230, 234, 243, 245, 247-249

product life cycle 21

public intervention 37

revealed competitive advantage, RCA 62, 97-99, 212-213, 217

R\&D 26-30, 37, 48, 59, 70, 172, 193, 206-207, 217, 222, 228, 231, 237-239, 247

regional exports $2,29,58,60-61,66,68,72$, $87-91,94-96,99-100,102,138,148,150$, $160,207,210,212-213,228,230,247,251$

Ricardian model 28

rural regions 70

small open economy, SOE 2, 6, 13-14, 18, 104, 115, 220, 226, 231

smart specialisation, SS 2, 18, 76, 97, 138, 159, 202, 205-210, 212-214, 216-217, 221-223, 225, 235-237, 244-245, 249

smart specialisation strategy 202, 206 
specialisation 1-2, 10, 12, 14, 18, 22, 29-30, 39, 55-56, 67, 76, 96-97, 138, 150, 159, 189, 202-203, 205-206, 209-211, 221-223, 225 , 233, 235-237, 244-245, 249

spillovers 27-28, 36-37, 47-49, 51, 53, 60, 68-70, 224, 227-228, 231, 238-239, 242-243, 248, 250

steady-state $25-27,29,36$

subsidiarity $2,17-18,57,73,115$ technological development 11 technology accumulation 22, 28 technology diffusion 27-29, 48-49, 239 trade profile 8 trade theory 1-2, 7, 23, 30, 60, 64, 96, 220-221 urban areas 55, 70, 76 vulnerability $12,17,64,67,73,86,89,96-97$, 103, 137, 221-222, 244 